\title{
Viabilidad de Lactobacillus plantarum microencapsulado bajo condiciones gastrointestinales simuladas e inhibición sobre Escherichia coli 0157:H7
}

\section{Viability of microencapsulated Lactobacillus plantarum under simulated gastrointestinal conditions and inhibition against Escherichia coli 0157:H7}

\author{
Catalina Fajardo-Argoti ${ }^{1}$ Henry Jurado-Gámez ${ }^{2}$; Jaime Parra-Suescún ${ }^{3}$
}

\begin{abstract}
'Zootecnista, Estudiante Maestría en Ciencias Agrarias. Universidad Nacional de Colombia, Facultad de Ciencias Agrarias, Grupo de Investigación Procesos Biotecnológicos Aplicados a la Producción Animal-Forrajes y Apicultura, PROBIOTEC-FORAPIS. Medellín - Antioquia, Colombia; email: ifajardo@unal.edu.co; (D) https://orcid.org/0000-0003-1993-6573

${ }^{2}$ Zoot, Esp., M.Sc., Ph.D. Universidad de Nariño, Facultad de Ciencias Pecuarias, Grupo de Investigación Procesos Biotecnológicos Aplicados a la Producción AnimalForrajes y Apicultura, PROBIOTEC-FORAPIS. Pasto - Nariño, Colombia; email: henryjugam@gmail.com; (D) https://orcid.org/0000-0003-2118-7997

${ }^{3}$ Zoot, M.Sc., Ph.D. Universidad Nacional de Colombia, Facultad de Ciencias Agrarias, Grupo de Investigación Biodiversidad y Genética Molecular, BIOGEM. Medellín - Antioquia, Colombia; email: jeparrasu@unal.edu.co; (D) https://orcid.org/0000-0003-4772-1326
\end{abstract}

Cómo citar: Fajardo-Argoti, C.; Jurado-Gámez, H.; Parra-Suescún, J. 2021. Viabilidad de Lactobacillus plantarum microencapsulado bajo condiciones gastrointestinales simuladas e inhibición sobre Escherichia coli O157:H7. Rev. U.D.C.A Act. \& Div. Cient. 24(1):e1733. http://doi.org/10.31910/rudca.v24.n1.2021.1733

Artículo de acceso abierto publicado por Revista U.D.C.A Actualidad \& Divulgación Científica, bajo una licencia Creative Commons CC BY-NC 4.0

Publicación oficial de la Universidad de Ciencias Aplicadas y Ambientales U.D.C.A, Institución de Educación Superior Acreditada de Alta Calidad por el Ministerio de Educación Nacional.

Recibido: agosto 8 de 2020 Aceptado: mayo 18 de 2021 Editado por: Helber Adrián Arévalo Maldonado

\section{RESUMEN}

Los Lactobacillus inhiben múltiples agentes patógenos causales de toxiinfecciones alimentarias, relacionándose su mecanismo de acción con la modulación del sistema inmune. Por su parte, E. coli O157:H7 es considerado un microorganismo causal de alteraciones, principalmente, a nivel intestinal y renal y es encontrado, por lo general, en matrices alimentarias contaminadas o en mal estado. La incidencia de este tipo de problemática se ha relacionado a la resistencia a los antibióticos, que limita su control y mitigación de manera eficaz. Por lo tanto, el objetivo del trabajo fue evaluar el efecto inhibitorio de Lactobacillus plantarum microencapsulado in vitro sobre Escherichia coli O157:H7, con el fin de encontrar estrategias inocuas para el control de agentes patógenos. Se determinó la cinética de fermentación, evaluando variables, como consumo de azúcar, producción de proteínas, acidez, pH y fase logarítmica (UFC/mL). La microencapsulación, se realizó mediante la técnica de spray drying, utilizando inulina y maltodextrina, como materiales encapsulantes. Se determinó la viabilidad de L. plantarum bajo condiciones gastrointestinales simuladas. Además, se evaluaron las características físicas del microorganismo microencapsulado y el efecto inhibitorio de L. plantarum y su sobrenadante sobre E. coli O157:H7. Posteriormente, se valoró la susceptibilidad de ambas cepas a diferentes antibióticos. Como resultado, se encontró resistencia de ambas cepas a algunos antibióticos evaluados, como penicilina. La cepa láctica y el sobrenadante inhibieron el crecimiento de E. coli 
O157:H7. L. plantarum presentó una viabilidad óptima a condiciones gastrointestinales simuladas después de 45 días de almacenamiento $\left(1,4 \times 10^{7}-3,0 \times 10^{10} \mathrm{UFC} / 150 \mu \mathrm{L}\right)$. La microencapsulación incrementa su vialidad y su establecimiento en el huésped.

Palabras clave: Sanidad animal; Probiótico; Lactobacillus; Patógeno.

\section{ABSTRACT}

Lactobacillus inhibit multiple pathogens that cause food poisoning, and their mechanism of action is related to the modulation of the immune system. E. coli $\mathrm{O} 157: \mathrm{H} 7$ is considered a causal microorganism of alterations, mainly at intestinal and renal level, and is generally found in contaminated or spoiled food matrices. The incidence of this type of problem has been related to antibiotic resistance, which limits its effective control and mitigation. Therefore, the objective of this work was to evaluate the inhibitory effect of microencapsulated Lactobacillus plantarum in vitro on Escherichia coli $\mathrm{O} 157: \mathrm{H} 7$, in order to find innocuous strategies for the control of pathogens. Fermentation kinetics were determined by evaluating variables such as sugar consumption, protein production, acidity, $\mathrm{pH}$ and logarithmic phase $(\mathrm{CFU} / \mathrm{mL})$. Microencapsulation was performed by spray drying, using inulin and maltodextrin as encapsulating materials. The viability of $L$. plantarum was determined under simulated gastrointestinal conditions. In addition, the physical characteristics of the microencapsulated microorganism and the inhibitory effect of $L$. plantarum and its supernatant on E. coli O157:H7 were evaluated. Subsequently, the susceptibility of both strains to different antibiotics was evaluated. As a result, resistance of both strains to some of the antibiotics evaluated, such as penicillin, was found. The lactic strain and the supernatant inhibited the growth of E. coli O157:H7. L. plantarum showed optimal viability at simulated gastrointestinal conditions after 45 days of storage $\left(1.4 \times 10^{7}-3.0 \times 10^{10} \mathrm{CFU} / 150 \mu \mathrm{L}\right)$. Microencapsulation increases its viability and establishment in the host.

Keywords: Animal health; Probiotic; Lactobacillus; Pathogen.

\section{INTRODUCCIÓN}

Alrededor del 30\% de las enfermedades infecciosas emergentes en los últimos 60 años son provocadas por microorganismos que se transmiten, a través de productos comestibles (McLinden et al. 2014). Un factor importante en la incidencia de las Toxiinfecciones Alimentarias (TIA) es la resistencia a los agentes antimicrobianos o antibióticos, por su uso indiscriminado en las producciones pecuarias (Jurado-Gámez \& Zambrano-Mora, 2020). En este sentido, el Centro de Prevención y Control de Enfermedades de la Unión Europea (ECDC) y la Autoridad Europea de Seguridad Alimentaria (EFSA), alertan sobre el aumento de la resistencia a los antibióticos de cepas de E. coli, que es una de las bacterias más común en los alimentos contaminados (EFSA \& ECDC, 2018).

Los microorganismos benéficos incrementan el valor nutricional y la supervivencia y disminuyen la incidencia de enfermedades causadas por bacterias patógenas (García et al. 2016). De acuerdo con la Organización de las Naciones Unidas para la Agricultura y la Alimentación (FAO) y la Organización Mundial de la Salud (OMS) definen a los probióticos como microorganismos vivos que, cuando se administran en cantidades adecuadas, confieren un beneficio para la salud del huésped (FAO/WHO, 2002). En el área de sanidad y producción animal, Cossio et al. (2018) señalan que la aplicación de estos microorganismos se relaciona con la estabilización y la protección del ecosistema gastrointestinal, mejoras en los procesos metabólicos y digestivos, así como también en la modulación del sistema inmune. Dentro de la categoría de los probióticos, se encuentran las Bacterias Ácido Lácticas (BAL), consideradas seguras y utilizadas en muchos países en la producción de alimentos fermentados, controlando el crecimiento de patógenos. Por lo general, las cepas empleadas para el desarrollo de alimentos probióticos son aisladas de humanos, ya que poseen mayor posibilidad de adherirse y colonizar el epitelio intestinal; sin embargo, se ha demostrado que cepas de origen animal también poseen efectos favorables en el humano (Ruiz et al. 2017).

El género Lactobacillus comprende un gran grupo heterogéneo de bacterias anaerobias facultativas, no esporulantes, Gram positivas. Incluye especies, como L. plantarum, L. acidophilus, L. rhamnosus, L. bulgaricus, L. casei y L. reuteri (Duar et al. 2017). Por su parte, $L$. plantarum es una especie bacteriana asociada a especies vegetales y al tracto gastrointestinal (TGI) de humanos, ratones y cerdos. Esta bacteria puede fermentar un amplio espectro de carbohidratos vegetales; es tolerante a las sales biliares y a un $\mathrm{pH}$ bajo y posee una producción de sustancias antimicrobianas y bacteriocinas contra los patógenos intestinales (Betancur et al. 2020). A pesar que se ha demostrado la capacidad de las BAL de sobrevivir en el tracto gastrointestinal (Montalban-Arques et al. 2015) es fundamental favorecer su supervivencia, lo cual, se puede obtener mediante la técnica de microencapsulación.

Por lo expuesto anteriormente, el objetivo del presente trabajo de investigación fue evaluar la viabilidad de L. plantarum microencapsulado bajo condiciones gastrointestinales simuladas y su actividad inhibitoria sobre E. coli $\mathrm{O} 157: \mathrm{H} 7$, cuyos hallazgos van en dirección a generar una potencial alternativa de control de agentes bacterianos importantes, en las infecciones de origen alimentario.

\section{MATERIALES Y MÉTODOS}

La investigación, se realizó en el Laboratorio de Microbiología del Grupo de Investigación PROBIOTEC-FORAPIS y en los laboratorios especializados de la Universidad de Nariño. Se utilizaron L. plantarum ATCC ${ }^{\circledR} 8014$ y E. coli O157:H7 ATCC $® 43888$. La obtención y ajuste del inóculo, se realizó de acuerdo con lo descrito por Jurado et al. (2014).

Los parámetros cinéticos de L. plantarum, se evaluaron en medio MRS comercial; para esto, se tomaron muestras y mediciones cada 2:50h, de las siguientes variables: conteo de microorganismos viables en placa (UFC/mL) (Lanara, 1981), pH, consumo de azúcar (mg/L) (Dubois et al. 1956), producción de proteína (mg/L) (Lowry et al. 1951) y producción de ácido láctico (\%). La biomasa, se determinó 
a través del método propuesto por Crueger \& Crueger (1993), así como otras variables cinéticas de crecimiento (velocidad específica de crecimiento, tiempo de duplicación celular, cosecha máxima y tiempo de generación). Finalmente, se tomó una muestra de sobrenadante de L. plantarum y, por HPLC-DAD, se determinó el contenido de péptidos y de aminoácidos; para lo anterior, se ajustó, por espectrofotometría, a una densidad óptica 0,125 , en escala McFarland patrón 0,5 (1,5 × $10^{8}$ bacterias/mL). Luego, se trasfirieron muestras en tubos Eppendorf y se centrifugaron a $18.000 \mathrm{rpm}$, durante $30 \mathrm{~min}$, a $4^{\circ} \mathrm{C}$. Por último, el sobrenadante se filtró, utilizando membranas PVDF de 0,2micras y se llevó a lectura.

Una vez obtenidos los datos cinéticos para el proceso de encapsulación, se realizó el ajuste del inóculo, en donde a L. plantarum, se llevó a incubación, a $37^{\circ} \mathrm{C}$, por $24 \mathrm{~h}$, a una proporción, según Crueger \& Crueger (1993), del 10\% v/v, es decir, en $90 \mathrm{~mL}$ de caldo MRS estéril, se añadió $10 \mathrm{~mL}$ del inóculo bacteriano. Para el conteo, se tomó $1 \mathrm{~mL}$ y se llevó a lectura directa en espectrofotómetro, a $625 \mathrm{~nm}$. El patrón en la escala de McFarland, a la cual, se ajustó la población bacteriana, fue de 4 , equivalente a $1,2 \times 10^{9} \mathrm{UFC} / \mathrm{mL}$. Posteriormente, de acuerdo con Rodríguez et al. (2012), se preparó para el microorganismo una suspensión, que consistió en la adición del $15 \% \mathrm{p} / \mathrm{v}$, en relación $1: 1 \mathrm{p} / \mathrm{p}$ de los agentes microencapsulantes inulina y maltodextrina y, posteriormente, se inoculó con $10^{9} \mathrm{UFC} / \mathrm{g}$ del microorganismo. Para esto, se utilizó el equipo de secado por aspersión Secador Spray Bilon $6000 \mathrm{~s} \circledR$, con una temperatura de entrada de $170^{\circ} \mathrm{C}$ y una temperatura de salida de $66^{\circ} \mathrm{C}$, con ciclo completo de $2 \mathrm{~h}$ y $30 \mathrm{~min}$, para un flujo de alimentación de $400 \mathrm{~mL}$, del total de inóculo.

Se evaluó el rendimiento del microencapsulado después del secado por aspersión razón de BAL microencapsulado, respecto al adicionado en la solución, de acuerdo con Pulido \& Beristain (2010). De igual manera, se determinaron las siguientes propiedades físicas del microencapsulado: actividad de agua, humedad relativa, solubilidad, humectabilidad, higroscopicidad y eficiencia de microencapsulación $(\% \mathrm{EE}=(\mathrm{A}-\mathrm{B} / \mathrm{A}) \mathrm{X} 100$; siendo $\mathrm{A}$, la concentración bacteriana antes de la microencapsulación y B es la concentración de la bacteria después de microencapsular, encontrada en el sobrenadante), siguiendo las metodologías propuestas por Rodríguez-Barona et al. (2016) y González et al. (2015). Además, se determinó el tamaño y la morfología de las microcápsulas, utilizando un microscopio electrónico de barrido FEG (Field Emission Gun) - QUANTA 650 FEG. Dicho análisis fue realizado en el laboratorio del Centro de Microscopía y Microanálisis (Bogotá, Colombia). El material microencapsulado, se almacenó a temperatura ambiente del laboratorio de investigación, de $20 \pm 2^{\circ} \mathrm{C}$, durante 45 días.

Después de realizada la microencapsulación, se determinó el crecimiento de $L$. plantarum microencapsulado en condiciones gastrointestinales simuladas, con concentraciones de sales biliares bovinas, de 0,3 y $1 \%$ y bilis bovina, de 0,3 y $0,5 \%$ y a niveles, de $\mathrm{pH}$ de 3,0 y 7,0. La incubación, se realizó en condiciones de aerobiosis en medio MRS comercial, a $37^{\circ} \mathrm{C}$, durante $48 \mathrm{~h}$ y el ajuste del $\mathrm{pH}$, se realizó con ácido tartárico (Freudig et al. 1999). Adicionalmente, se evaluó la resistencia a lisozima, sometiendo la cepa láctica a diferentes preparaciones de lisozima: (i) $0,6 \mu \mathrm{L}$ de cultivo y $0,60 \mu \mathrm{g}$ de lisozima, (ii) $0,6 \mu \mathrm{L}$ de cultivo y $120 \mu \mathrm{g}$ de lisozima, (iii) $0,6 \mu \mathrm{L}$ de cultivo y $180 \mu \mathrm{g}$ de lisozima. Se llevó a incubación, durante $24 \mathrm{~h}$, a $37^{\circ} \mathrm{C}$.

Para evaluar el efecto inhibitorio de L. plantarum, de acuerdo con la metodología de Tagg \& McGiven (1971), los volúmenes trabajados en los métodos discos de agar, doble capa y difusión en pozos fueron de 90,125 y $150 \mu \mathrm{L}$ y para el método discos modificado (PADS) fueron de 80, 90 y $100 \mu \mathrm{L}$, respectivamente. Además, se verificó la producción de exopolisacáridos (EPS), de acuerdo con lo descrito por Elinalva Maciel et al. (2012), donde se utilizaron discos de papel de filtro estéril $(5 \mathrm{~mm})$, impregnados con $5 \mu \mathrm{L}$ de cultivo láctico, en placas de Petri, con agar MRS, para observar la producción de EPS (Guimarães et al. 1999). El ensayo, se realizó bajo las siguientes condiciones: diferentes niveles de $\mathrm{pH}(6,0 \pm 0,2$ y $7,5 \pm 0,2)$, temperatura $\left(28 \pm 2^{\circ} \mathrm{C}, 35 \pm 2^{\circ} \mathrm{C}\right.$ y $\left.42 \pm 2^{\circ} \mathrm{C}\right)$ y tiempos de incubación (24h, $48 \mathrm{~h}$ y 7 días). Finalmente, se evaluó la susceptibilidad de $L$. plantarum y E. coli O157:H7 frente a los antibióticos penicilina (10UI), cefalotina (KF $30 \mu \mathrm{g})$, ciprofloxacina (CIP $5 \mu \mathrm{g})$, gentamicina (CN

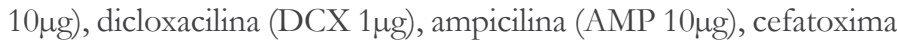

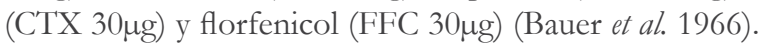

En este orden de ideas, los parámetros de la cinética de crecimiento se realizaron cada 2,5 horas, con 8 muestreos para cada variable; con la información recolectada, se obtuvo el promedio para cada punto y se realizaron las curvas de evolución en el tiempo para los parámetros. La evaluación de la microencapsulación, se realizó por triplicado para cada uno de los parámetros (rendimiento y propiedades físicas), obteniendo la media como resultado. Para la susceptibilidad de las cepas a los diferentes antibióticos, se usaron 8 repeticiones. El mismo número de réplicas se hicieron en las pruebas de inhibición. Los resultados fueron organizados en hoja de cálculo Excel ${ }^{\circledR}$ y los análisis se realizaron en el software estadístico R (4.0.0, 2018). Para todas las variables, se determinaron los parámetros descriptivos, como la media y la desviación estándar.

\section{RESULTADOS Y DISCUSIÓN}

Según la información obtenida en la cinética de fermentación, se encontró que $L$. plantarum alcanzó su fase exponencial a las 11:50 horas y los valores de consumo de azúcares, producción de proteínas, ácido láctico y $\mathrm{pH}$, se muestran en la figura 1 . $\mathrm{Al}$ respecto, Agudelo et al. (2010) mencionan que, hasta las 24 horas de fermentación, la bacteria se reproduce sin limitación de sustancias nutritivas a velocidad máxima. De acuerdo con lo anterior, se puede observar que la variable $\mathrm{Ln} \mathrm{UFC} / 150 \mu \mathrm{L}$ de $L$. plantarum presentó diferencias estadísticas significativas $(\mathrm{P} \leq 0,05)$, entre el tiempo 11:50, donde tuvo lugar el máximo crecimiento y los tiempos 0:0, 2:50, 14:50, 20:50 y 23:50, confirmando la tendencia del microorganismo observado en la cinética. En cuanto al consumo de azúcares y producción de proteínas, en la fase exponencial, fue de $6,98 \mathrm{mg} / \mathrm{L}$ y de $4,88 \mathrm{mg} / \mathrm{L}$, respectivamente. En este sentido, la BAL en estudio puede ser utilizada en la industria alimentaria por su rendimiento, que se traduce en la obtención de productos en menor tiempo, generando menores costos de producción. Asimismo, L. plantarum obtuvo un 
número de generaciones por hora de 4,62, una cosecha máxima de

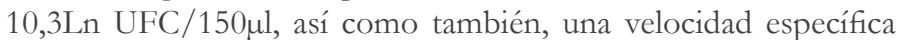
de crecimiento de 2,872 y un tiempo de duplicación celular de $14,47 \mathrm{~min}$, valores relativamente altos, en contraste con lo reportado por Agudelo et al. (2010), que fueron de 0,53 y 1,28, respectivamente; sin embargo, otros autores, como Jurado et al. (2015), reportaron valores de 0,98 y 42,42, respectivamente. Es de considerar que la velocidad y el tiempo de duplicación dependen de la concentración de nutrientes; así, a altas concentraciones, la velocidad específica alcanza valores máximos (Agudelo et al. 2010). En cuanto al pH y ácido láctico, los mismos autores señalan que, en los productos derivados de la fermentación, se encuentran altas concentraciones de ácido láctico y otros ácidos orgánicos, como productos finales del proceso catabólico de Lactobacillus y, en esta investigación, el descenso del pH para L. plantarum, en el medio MRS, pasó de 5,6 a 4,27 y que tiene un efecto inhibidor sobre el crecimiento de patógenos a estos $\mathrm{pH}$ alcanzados, por las BAL (Jurado Gámez et al. 2019). En cuanto a la identificación del perfil de péptidos para la cepa láctica, se detectaron 4 espectros UV, obtenidos a 214 y 280nm, correspondiente al péptido de composición VAL-TIR-VAL (PM = $379,5)$, con una concentración de $0,52 \mathrm{mg} / \mathrm{mL}$, similar a lo reportado por Jurado et al. (2015), en lo que respecta a valina y tirosina. En el perfil de aminoácidos en el sobrenadante de la BAL, se encontró lo siguiente: cantidad relativa porcentual \%: A. aspártico: 5,1; Serina: 9,7; Arginina: 7,6; Tirosina: 4,5; Valina: 10,4. Y, 5 aminoácidos para la cepa patógena (A. aspártico: 4,0; Serina: 7,5; Arginina: 6,0; Tirosina: 43,5; Valina: 15,5). Este parámetro es importante por la actividad inhibidora de las BAL en la producción de bacteriocinas de ser bactericidas o bacteriostáticos frente a microorganismos sensibles de la misma especie o estrechamente relacionados (Svetoslav et al. 2018). Egan et al. (2016) sostienen que las bacteriocinas son una defensa para las bacterias productoras, inhibiendo o destruyendo aquellas bacterias sensibles, que compiten por el mismo nicho ecológico. Por su parte, Castellano et al. (2017) mencionan que son inocuas para los consumidores y tampoco afectan la microbiota intestinal, ya que se inactivan en el sistema digestivo.

Se determinó la viabilidad de $L$. plantarum (UFC/g y \%), antes $\left(6,0 \times 10^{8} \mathrm{UFC} / \mathrm{g}\right)$ y después $\left(3,2 \times 10^{8} \mathrm{UFC} / \mathrm{g}-50 \%\right.$ viabilidad $)$ de la microencapsulación, después de 45 días de almacenamiento, a $20 \pm 2{ }^{\circ} \mathrm{C}$. En la viabilidad, bajo condiciones gastrointestinales simuladas, se observó un mejor crecimiento, con valores de $3,8 \times 10^{9}$ UFC/150 $\mu \mathrm{L}$, óptimo para el establecimiento, a nivel intestinal (Tabla 1). En complemento, la viabilidad de L. plantarum, en presencia de las diferentes preparaciones de lisozima, estuvo entre $2,0 \times 10^{9} \mathrm{y}$ $3,0 \times 10^{12} \mathrm{UFC} / 150 \mu \mathrm{L}$. Al respecto, Gutiérrez-Sarmiento et al. (2020) mencionan que la supervivencia de los microorganismos, a través del tracto gastrointestinal, es un criterio probiótico importante, ejerciendo un efecto benéfico en la salud del consumidor.

En la evaluación del material microencapsulado físicamente, se encontraron los siguientes valores: humedad (7,054\%), Aw $(0,400)$, higroscopicidad $(7,01 \mathrm{~g}$ humedad/100g de sólido seco), humectabilidad (1,56min), solubilidad $(92 \%)$ y eficiencia (42\%), estas determinaciones se realizaron cada 10 días. Adicionalmente, el rendimiento del proceso de secado fue del $40 \%$ y su viabilidad fue superior al nivel mínimo de $6,0 \log \mathrm{UFC} / \mathrm{g}$, recomendado por FAO/OMS (2002), como la cantidad requerida para producir beneficios terapéuticos y, ligeramente mayor, a la reportada por Rodríguez et al. (2012), la cual, fue de 46,53\%, con una matriz de Inulina, a una temperatura de entrada de $150^{\circ} \mathrm{C}$ y de salida de $90^{\circ} \mathrm{C}$, después de 21 días de almacenado. Estos resultados fueron más altos que los observados por Kingwatee et al. (2015), en el secado por atomización del jugo de lichi suplementado con L. casei 01, utilizando materiales de pared, como maltodextrina y goma arábiga, mezclados o no con inulina. Los polvos producidos a la temperatura de salida más alta mostraron una menor viabilidad y recuentos de células (2,46 y 4,73log $\mathrm{UFC} / \mathrm{g})$, en comparación con los producidos a $60^{\circ} \mathrm{C}(5,75$ y $6,80 \log \mathrm{UFC} / \mathrm{g})$. La alta viabilidad encontrada para la BAL, en este estudio, puede ser atribuida al efecto termoprotector de la inulina. Fritzen-Freire et al. (2012) estudiaron la microencapsulación de Bifidobacterium BB-12, mediante secado por aspersión, utilizando leche descremada reconstituida, como material de pared, en presencia de inulina y oligofructosa. Los valores porcentuales para la eficiencia de microencapsulación son similares a los reportados por González et al. (2015); para esta última, fue 50\% inferior en el presente estudio, debido, quizá, a que se evaluó una matriz de alginato (AS) y goma gelana de alto acilo (GAA).

La caracterización morfológica por microscopía electrónica de barrido reflejó que el microorganismo presentó una cápsula de forma simple y uniforme, sin grietas ni abultamientos (Figura 2), evidenciando la eficiencia de la matriz microencapsulante y una garantía para el correcto desempeño del microorganismo, en el lugar de adhesión. De esta manera, se obtuvieron tamaños con un rango entre 1,566 y $8,55 \mu \mathrm{m}$, similares a los reportados por Rodríguez et al. (2012) y Paim et al. (2016), donde el tamaño osciló entre 6,23 y $9,13 \mu \mathrm{m}$. El tamaño de las partículas es importante, ya que afecta el flujo del polvo, la capacidad de rehidratación, la solubilidad y la dispersabilidad, así como la compactación y la segregación de una mezcla de componentes. Según Schubert (1993), los polvos muy finos pueden tener una humectabilidad baja, debido a la alta tensión superficial, que conduce a la formación de una "capa viscosa" en la superficie del líquido, que dificulta el flujo de la capilaridad, a través de los poros intergranulares. El objetivo de la microencapsulación fue otorgar protección a $L$. plantarum frente a entornos que puedan afectar significativamente su desempeño y la expresión de su potencial probiótico, mantener su viabilidad durante el almacenamiento y asegurar su supervivencia frente a las enzimas digestivas y bilis del tracto gastrointestinal, permitiendo, en el intestino, conferir sus efectos beneficiosos al huésped. La resistencia a las condiciones gastrointestinales depende de las especies y de las cepas (Monteagudo-Mera et al. 2012) y la elección de la matriz del portador es decisiva para mejorar la supervivencia y la viabilidad en el colon. La incorporación de la matriz maltodextrina-inulina confirió una protección eficaz contra el jugo gástrico de bajo $\mathrm{pH}$ y la presencia de inulina mejoró aún más la recuperación de células viables, al final de la digestión simulada. Así, pues, las microcápsulas son vehículos valiosos para la liberación controlada de fármacos y de probióticos. 

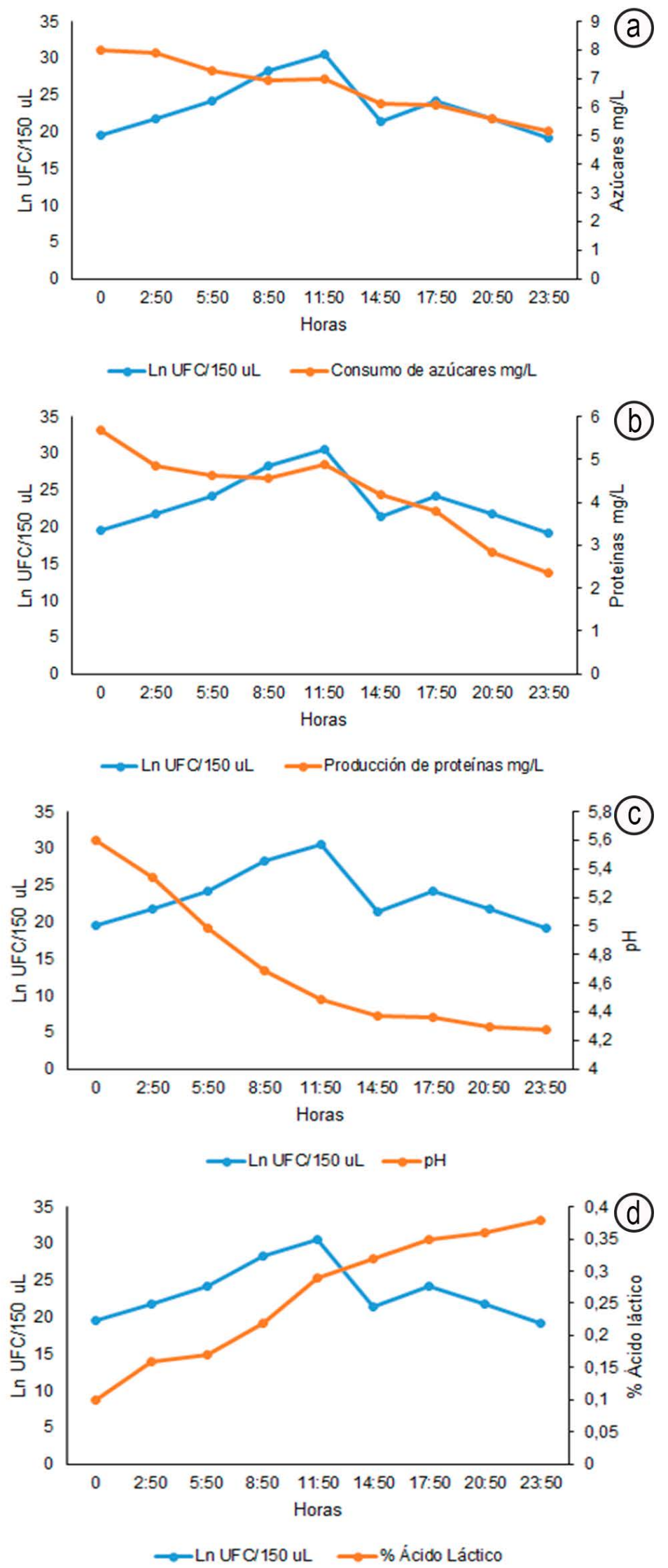

Figura 1. Crecimiento de Lactobacillus plantarum (Ln UFC/150 $\mu \mathrm{L}$ ) vs Variables evaluadas durante la cinética de fermentación. a. consumo de azúcares mg/L; b. producción de proteínas mg/L; c. pH; d. \% ácido láctico. 
Tabla 1. Valores de crecimiento de L. plantarum microencapsulado a 45 días y viabilidad, bajo condiciones gastrointestinales simuladas.

\begin{tabular}{|c|c|c|c|}
\hline \multicolumn{4}{|c|}{ L. plantarum antes del proceso de microencapsulación } \\
\hline Dilución sembrada & $10^{-5}$ & $10^{-6}$ & $10^{-7}$ \\
\hline $\mathrm{UFC} / 150 \mu \mathrm{L}$ & $6,0 \times 10^{7}$ & $6,0 \times 10^{8}$ & $6,0 \times 10^{9}$ \\
\hline \multicolumn{4}{|c|}{ Prueba de Viabilidad $>45$ días } \\
\hline Dilución & $10^{-5}$ & $10^{-6}$ & $10^{-7}$ \\
\hline $\mathrm{UFC} / 150 \mu \mathrm{L}$ & $3,0 \times 10^{7}$ & $2,7 \times 10^{8}$ & $3,0 \times 10^{9}$ \\
\hline \multicolumn{4}{|c|}{$\begin{array}{c}\text { Viabilidad bajo condiciones gastrointestinales } \\
\text { simuladas } \mathrm{pH} 3,0\end{array}$} \\
\hline Dilución & $10^{-5}$ & $10^{-6}$ & $10^{-7}$ \\
\hline $\mathrm{UFC} / 150 \mu \mathrm{L}$ & $3,6 \times 10^{7}$ & $4,0 \times 10^{8}$ & $3,8 \times 10^{9}$ \\
\hline \multicolumn{4}{|c|}{$\begin{array}{l}\text { Viabilidad bajo condiciones gastrointestinales } \\
\text { simuladas pH 6,5 (Sales biliares-SB) }\end{array}$} \\
\hline \multicolumn{4}{|c|}{ Concentración $0,3 \%(\mathrm{SB})$} \\
\hline Dilución & $10^{-5}$ & $10^{-6}$ & $10^{-7}$ \\
\hline $\mathrm{UFC} / 150 \mu \mathrm{L}$ & $2,0 \times 10^{7}$ & $1,8 \times 10^{5}$ & $3,1 \times 10^{9}$ \\
\hline \multicolumn{4}{|c|}{ Concentración 1\%(SB) } \\
\hline Dilución & $10^{-5}$ & $10^{-6}$ & $10^{-7}$ \\
\hline $\mathrm{UFC} / 150 \mu \mathrm{L}$ & $3,5 \times 10^{7}$ & $6,3 \times 10^{8}$ & $3,1 \times 10^{9}$ \\
\hline \multicolumn{4}{|c|}{$\begin{array}{c}\text { Viabilidad bajo condiciones gastrointestinales } \\
\text { simuladas } \mathrm{pH} \text { 6,5 (Bilis-B) }\end{array}$} \\
\hline \multicolumn{4}{|c|}{ Concentración $0,5 \%(B)$} \\
\hline Dilución & $10^{-5}$ & $10^{-6}$ & $10^{-7}$ \\
\hline $\mathrm{UFC} / 150 \mu \mathrm{L}$ & $3,1 \times 10^{7}$ & $2,9 \times 10^{8}$ & $3,0 \times 10^{9}$ \\
\hline
\end{tabular}

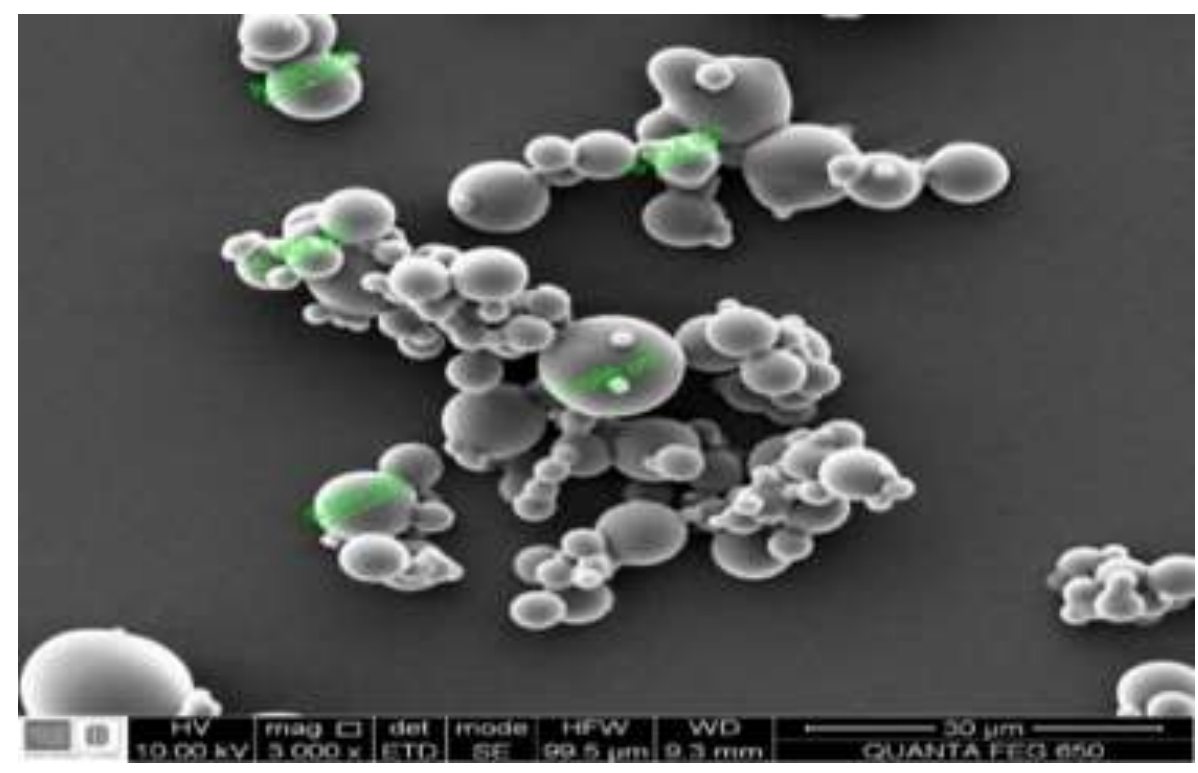

Figura 2. Microfotografía de Lactobacillus plantarum microencapsulado. 
En la prueba de susceptibilidad frente a agentes antimicrobianos, $L$. plantarum y E. coli O157:H7 mostraron la mayor sensibilidad frente a CTX y CIP (Tabla 2). Sánchez de Ramos et al. (2011) reportaron una resistencia a los antibióticos gentamicina y ciprofloxacina en cepas de Lactobacillus. En cuanto a la sensibilidad/resistencia de E. coli $\mathrm{O} 157: \mathrm{H} 7$ fueron similares a los reportados por Toledo et al. (2015) en AMP y KF y sensibilidad a CIP y CN. Cueto-Vigil et al. (2010) afirman que las bacterias intestinales comensales, incluyendo a las BAL, actúan como reservorios de genes de resistencia a antibióticos similares a los encontrados en patógenos humanos, transfiriéndolos a bacterias patógenas, a través de plásmidos o transposones. Wendlandt et al. (2015) plantean que la diseminación de cepas resistentes son producto de infecciones alimentarias adquiridas por el contacto con productos contaminados, donde el hospedero es infectado o colonizado con el microorganismo resistente. Al respecto, Cueto \& Aragón (2012) establecen que la estructura de la pared celular de las especies Gram positivas es gruesa (como en el caso de las BAL) y en las Gram negativas es muy delgada, lo cual, puede ser un factor que induzca a su sensibilidad a los antibióticos.

Los ensayos de inhibición in vitro de L. plantarum y su sobrenadante por el método de discos modificado (PADS) frente a E. coli O157:H7 mostraron la mayor susceptibilidad a una concentración de $90 \mu \mathrm{L}$ (Tabla 3). Esta acción inhibitoria, se atribuye a sustancias como ácidos orgánicos, peróxido de hidrógeno, bacteriocinas, entre otras, favoreciendo un ambiente favorable para la microbiota benéfica y el huésped (Heredia-Castro et al. 2017). La respuesta antagónica e inocua en los halos de L. plantarum es similar a lo reportado por VeraMejía et al. (2018). Por su parte, Abramov et al. (2014) y Sánchez et al. (2015) mencionan que la producción del peróxido de hidrógeno y ácido láctico por Lactobacillus no permite la colonización por microorganismos patogénicos, alterando su permeabilidad celular, así como descenso del pH intracelular. En la determinación de presencia de EPS, se encontró un material translúcido asociado a una colonia mucoide y precipitación de la muestra en alcohol absoluto, indicando la potencial producción de EPS $\left(28\right.$ y $\left.35^{\circ} \mathrm{C}\right)$. Nácher Vásquez et al. (2016) consideran que intervienen en: capacidad de adhesión bacteriana, formación de biopelículas, protección de la integridad celular en diferentes ambientes y en su adaptación para colonizar el tracto digestivo o la mucosa vaginal, asociado a su capacidad para ser organismos simbióticos.

Se concluye que L. plantarum expresó su potencial probiótico al inhibir a E. coli O157:H7; la microencapsulación permitió el almacenamiento de L. plantarum. A pesar que la temperatura del secado por aspersión afectó un porcentaje de viabilidad, este efecto se contrarrestó por la excelente estabilidad durante el almacenamiento a temperatura ambiente, que se mantuvo después de 6 semanas. La matriz maltodextrina-inulina mejoró las tasas de supervivencia en condiciones gastrointestinales simuladas; sin embargo, un nuevo reto es encontrar un material con mayor afinidad con el microorganismo, para superar más eficazmente los pasos desde la producción hasta el almacenamiento y la digestión.

Tabla 2. Prueba de susceptibilidad frente a agentes antimicrobianos en L. plantarum frente a E. coli O157:H7.

\begin{tabular}{|c|c|c|c|c|}
\hline Antibiótico & Halo $(\mathbf{m m})$ & L. plantarum & Halo $\mathbf{( m m )}$ & E. coli \\
\hline CTX $30 \mu g$ & 35 & $\mathrm{~S}^{\mathrm{bc}}$ & 30 & $\mathrm{~S}^{\mathrm{a}}$ \\
\hline KF $\mathbf{3 0} \boldsymbol{\mu g}$ & 13 & $\mathrm{R}^{\mathrm{bc}}$ & 11 & $\mathrm{R}^{\mathrm{a}}$ \\
\hline CIP $\mathbf{5} \boldsymbol{\mu g}$ & 12 & $\mathrm{R}^{\mathrm{b}}$ & 35 & $\mathrm{~S}^{\mathrm{a}}$ \\
\hline CN $\mathbf{1 0} \boldsymbol{\mu g}$ & 13 & $\mathrm{R}^{\mathrm{b}}$ & 19 & $\mathrm{~S}^{\mathrm{a}}$ \\
\hline DCX $\mathbf{1} \boldsymbol{\mu g}$ & - & $\mathrm{R}^{\mathrm{b}}$ & - & $\mathrm{R}^{\mathrm{a}}$ \\
\hline P $\mathbf{1 0} \mathbf{I U}$ & 20 & $\mathrm{~S}^{\mathrm{b}}$ & - & $\mathrm{S}^{\mathrm{a}}$ \\
\hline AMP $\mathbf{1 0} \boldsymbol{\mu g}$ & - & $\mathrm{R}^{\mathrm{bc}}$ & - & $\mathrm{R}^{\mathrm{a}}$ \\
\hline FFC $\mathbf{3 0} \boldsymbol{\mu g}$ & 31 & $\mathrm{~S}^{\mathrm{b}}$ & 28 & $\mathrm{~S}^{\mathrm{a}}$ \\
\hline
\end{tabular}

CTX: Cefatoxima, KF: Cefalotina, CIP: Ciprofloxacina, CN: Gentamicina, DCX: Dicloxacilina, P: Penicilina, AMP: Ampicilina, FFC: Florfenicol. a: Manual para antibiograma LABORCLIN, b: Sánchez de Ramos et al. (2011), c: Charteris et al. (1998). 
Tabla 3. Concentraciones $(\mu \mathrm{L})$ y halos de inhibición $(\mathrm{mm})$ producidos por L. plantarum (discos de agar) y de su sobrenadante frente a $E$. coli O157:H7.

\begin{tabular}{|c|c|c|c|c|}
\hline \multirow{2}{*}{ Método } & \multirow{2}{*}{ Condición } & \multicolumn{3}{|c|}{ Concentración $(\mu \mathrm{L})$ y halo $(\mathrm{mm})$} \\
\hline & & $90 \mu \mathrm{L}$ & $125 \mu \mathrm{L}$ & $150 \mu \mathrm{L}$ \\
\hline Discos de agar & - & 9 & 5 & 4 \\
\hline \multirow{2}{*}{ Doble capa } & A & 4 & 5 & 6 \\
\hline & B & 4 & 2 & - \\
\hline \multirow{2}{*}{ Difusión en pozos } & A & 4 & 3 & 5 \\
\hline & $\mathbf{B}$ & 5 & 2 & 3 \\
\hline Método & Condición & $80 \mu \mathrm{L}$ & $90 \mu \mathrm{L}$ & $100 \mu \mathrm{L}$ \\
\hline \multirow{2}{*}{ Discos modificados (Pads) } & A & 4 & 3 & 4 \\
\hline & B & 8 & 4 & 6 \\
\hline
\end{tabular}

A: Filtrado a pH 6; B: Sin filtrar a pH 6.

Agradecimientos. Los autores de la presente investigación agradecen al grupo de investigación PROBIOTEC-FORAPIS de la Universidad de Nariño, por permitir el desarrollo y la ejecución de este trabajo de investigación, a nivel de Maestría.

\section{REFERENCIAS}

1. ABRAMOV, V.; KHLEBNIKOV, V.; KOSAREV, I.; BAIRAMOVA, G.; VASILENKO, R.; SUZINA, N.; MACHULIN, A.; SAKULIN, V.; KULIKOVA, N.; VASILENKO, N.; KARLYSHEV, A.; UVERSKY, V.; CHIKINDAS, M.; MELNIKOV, V. 2014. Probiotic Properties of Lactobacillus crispatus 2,029: Homeostatic Interaction with Cervicovaginal Epithelial Cells and Antagonistic Activity to Genitourinary Pathogens. Probiotics and Antimicrobial Proteins. 6(3-4):165-176. https://doi.org/10.1007/s12602-014-9164-4

2. AGUDELO, C.; ORTEGA, R.; HOYOS, J. 2010. Determination of kinetic parameters of two lactic inoculums: Lactobacillus plantarum A6 and Lactic Acid bacterias of yogurt. Ciencias Agropecuarias. 8(2):8-16.

3. BAUER, A.W.; KIRBY, W.M.; SHERRIS, J.C.; TURCK, M. 1966. Antibiotic Susceptibility Testing by a Standardized Single Disk Method. American Journal of Clinical Pathology. 45(4):493-496.

4. BETANCUR, H.C.; RODRÍGUEZ, B.R.; MARTÍNEZ, Y.; ROMERO C., O.; RUGELES, C.C. 2020. La administración oral de un biopreparado con Lactobacillus plantarum CAM6 mejoró el comportamiento productivo y el rendimiento de la canal de cerdos en crecimiento. Revista de Producción Animal. 32(2):64-73.

5. CASTELLANO, P.; PÉREZ IBARRECHE, M.; BLANCO MASSANI, M.; FONTANA, C.; VIGNOLO, G.M.
2017. Strategies for Pathogen Biocontrol Using Lactic Acid Bacteria and Their Metabolites: A Focus on Meat Ecosystems and Industrial Environments. Microorganisms. 38(5):1-25.

https://doi.org/10.3390/microorganisms5030038

6. CHARTERIS, W.P.; KELLY, P.M.; MORELLI, L.; COLLINS, K. 1998. Antibiotic susceptibility of potential probiotic Lactobacillus species. J. Food Protect. 61(12):1636-1643. https:/ /doi.org/10.4315/0362-028x-61.12.1636

7. COSSIO, D.S.; HERNÁNDEZ, Y.G.; MENDOZA, J.D. 2018. Development of probiotics for animal production. Experiences in Cuba Desarrollo de probióticos destinados a la producción animal: experiencias en Cuba. Cuban Journal of Agricultural Science. 52(4):1.

8. CRUEGER, W.; CRUEGER, A. 1993. Biotecnología: Manual de Microbiología Industrial. $3^{\circ} \mathrm{ed}$. Ed. Acribia (España). 432p.

9. CUETO, C.; ARAGÓN, S. 2012. Evaluación del potencial probiótico de bacterias ácido lácticas para reducir el colesterol in vitro. Scientia Agropecuaria. 3(1):45-50. https://doi.org/10.17268/sci.agropecu.2012.01.06

10. CUETO-VIGIL, M.C.; ACUÑ-MONSALVE, Y.; VALENZUELA-RIAÑO, J. 2010. Evaluación in vitro del potencial probiótico de bacterias ácido lácticas aisladas de suero costeño. Actualidades biológicas. 32(93):129-138.

11. DUAR, R.M.; LIN, X.B.; ZHENG, J.; MARTINO, M.E.; GRENIER, T.; PÉREZ-MUÑOZ, M.E.; LEULIER, F.; GÄNZLE, M.; WALTER, J. 2017. Estilos de vida en transición: evolución e historia natural del género Lactobacillus. FEMS Microbiol. Rev. 41(Supl. 1):S27-S48. https://doi.org/10.1093/femsre/fux030 
12. DUBOIS, M.; GILES, K.A.; HAMILTON, J.K.; REBERS, P.A.; SMITH, F. 1956. Colorimetric method for determination of sugar and related substances. Anal Chem. 28(3):350-356.

13. EGAN, K.; FIELD, D.; REA, M.C.; ROSS, R.P.; HILL, C.; COTTER, P.D. 2016. Bacteriocins: Novel Solutions to Age Old Spore Related Problems? Frontiers in Microbiology. 7(461):1-21. https://doi.org/10.3389/fmicb.2016.00461

14. ELINALVA MACIEL, P.; VASCONCELOS, M.P.; OLIVEIRA, I.S.; AFFE, H.M.D.J.; NASCIMENTO, R.; MELO, I.S.D.; ROQUE, M.R.A.; ASSIS, S.A.D. 2012. An alternative method for screening lactic acid bacteria for the production of exopolysaccharides with rapid confirmation. Food Science and Technology. 32(4):710-714. https://dx.doi.org/10.1590/S0101-20612012005000094

15. EUROPEAN FOOD SAFETY AUTHORITY, EFSA; EUROPEAN CENTRE FOR DISEASE PREVENTION AND CONTROL, ECDC. 2018. The European Union summary report on antimicrobial resistance in zoonotic and indicator bacteria from humans, animals and food in 2016. EFSA Journal. 16(2):e05182.

https://doi.org/10.2903/j.efsa.2018.5182

16. FOOD AND AGRICULTURE ORGANIZATION OF THE UNITED NATIONS-FAO; WORLD HEALTH ORGANIZATION- WHO. 2002. Guidelines for the evaluation of probiotics in food. Available from Internet in: https://www.who.int/foodsafety/fs_management/en/ probiotic_guidelines.pdf

17. FREUDIG, B.; HOGEKAMP, S.; SCHUBERT, H. 1999. Dispersion of powders in liquids in a stirred vessel. Chemical Engineering and Processing. 38:525-532.

18. FRITZEN-FREIRE, C.; PRUDÊNCIO, E.S.; AMBONI, R.D.; PINTO, S.S.; NEGRÃO-MURAKAMI, A.N.; MURAKAMI, F.S. 2012. Microencapsulation of bifidobacteria by spray drying in the presence of prebiotics. Food Research International. 45:306e312.

19. GARCÍA, Y.; PÉREZ, T.; BOUCOURT, R.; BALCÁZAR, J.L.; NICOLI, J.R.; MOREIRA, J.; RODRÍGUEZ, Z.; FUERTES, H.; NUÑEZ, O.; ALBELO, N.; HALAIHEL, N. 2016. Isolation, characterization and evaluation of probiotic lactic acid bacteria for potential use in animal production. Research in Veterinary Science. 108:125-132. https://doi.org/10.1016/j.rvsc.2016.08.009

20. GONZÁLEZ, R.E.; MENDOZA, J.; MORÓN, L.B. 2015. Efecto de la Microencapsulación sobre la Viabilidad de Lactobacillus delbrueckii sometido a Jugos Gástricos Simulados. Inf Tecnol. 26(5):11-16. http://dx.doi.org/10.4067/S0718-07642015000500003
21. GUIMARÃES, D.P.; COSTA, F.A.A.; RODRIGUES, M.I.; MAUGERI, F. 1999. Optimización de la síntesis de dextrano e hidrólisis ácida mediante análisis de respuesta de superficie. Revista Brasileña de Ingeniería Química. 16(2):129-139. http://dx.doi.org/10.1590/S0104-66321999000200004

22. GUTIÉRREZ-SARMIENTO, W.; VENTURA-CANSECO, L.M.; GUTIÉRREZ-MICELI, F.A.; LUJÁN-HIDALGO, M.C.; ABUD-ARCHILA, M.; RUÍZ-VALDIVIEZO, V.M. 2020. Optimización de producción de biomasa, ácido láctico y supervivencia a simulación gastrointestinal de Lactobacillus plantarum BAL-03-IT'TG cultivado en biorreactor de tanque agitado. Agrociencia. 54(2):147-162.

23. HEREDIA-CASTRO, P.; HÉRNÁNDEZ-MENDOZA, A.; GONZÁLEZ-CÓRDOVA, A.; VALLEJO-CORDOBA, B. 2017. Bacteriocinas de bacterias ácido lácticas: mecanismos de acción y actividad antimicrobiana contra patógenos en quesos. Interciencia. 42(6):340-346. https://doi.org/10.1093/ajcp/45.4_ts.493

24. JURADO GÁMEZ, H.; SINSAJOA TEPUD, M.; NARVÁEZ RODRÍGUEZ, M. 2019. Evaluación de Lactobacillus plantarum microencapsulado y su viabilidad bajo condiciones gastrointestinales simuladas e inhibición frente a Escherichia coli O157:H7. Revista de la Facultad de Medicina Veterinaria y de Zootecnia. 66(3):231-244.

https://doi.org/10.15446/rfmvz.v66n3.84260

25. JURADO, H.; CALPA, F.; CHASPUENGAL, A. 2014. Determinación in vitro de la acción probiótica de Lactobacillus plantarum sobre Yersinia pseudotuberculosis aislada de Cavia porcellus. Rev Fac Med Vet Zoot. 61(3):241-257. http://dx.doi.org/10.15446/rfmvz.v61n3.46872

26. JURADO, H.; JARRÍN, V.; PARREÑO, J. 2015. Crecimiento de L. plantarum y efecto sobre E. coli, S. typhimurium, S. aureus y C. perfringens. Biotecnología en el Sector Agropecuario y Agroindustrial. 13(2):57-66.

27. JURADO-GÁMEZ, H.; ZAMBRANO-MORA, E. 2020. Efecto de Lactobacillus casei microencapsulado sobre la salud intestinal y parámetros bioquímicos y productivos en pollo de engorde. Revista U.D.C.A Actualidad \& Divulgación Científica. 23(2):e1480. https://doi.org/10.31910/rudca.v23.n2.2020.1480

28. KINGWATEE, N.; APICHARTSRANGKOON, A.; CHAIKHAM, P.; WORAMETRACHANON, S.; TECHARUNG, J.; PANKASEMSUK, T. 2015. Spray drying Lactobacillus casei 01 in lychee juice varied carrier materials. LWT - Food Science and Technology. 62:847853.

https://doi.org/10.1016/j.lwt.2014.12.007 
29. LANARA, L. 1981. Métodos microbiológicos. 3aed. Ministerio de Agricultura (Brasilia).

30. LOWRY, O.; ROSEBROUG, N.; FAR, A.; RANDALL, R. 1951. Protein measurement with the folin phenol reagent. J. Biol Chem. 193(1):265-275.

31. MCLINDEN, T.; SARGEANT, J.M.; THOMAS, M.K.; PAPADOPOULOS, A.; FAZIL, A. 2014. Component costs of foodborne illness: a scoping review. BMC Public Health. 14:509.

https:/ /doi.org/10.1186/1471-2458-14-509

32. MONTALBAN-ARQUES, A.; DE SCHRYVER, P.; BOSSIER, P.; GORKIEWICZ, G.; MULERO, V.; GATLIN, D.M.; GALDINO-VILLEGAS, J. 2015. Selective manipulation of the gut microbiota improves immune status in vertebrates. Front. Immunol. 6:512. http://dx.doi.org/10.3389/fimmu.2015.00512

33. MONTEAGUDO-MERA, A.; RODRÍGUEZ-APARICIO, L.; RÚA, J.; MARTÍNEZ-BLANCO, H.; NAVASA, N.; GARCÍA-ARMESTO, M.R.; FERRERO, M.Á. 2012. In vitro evaluation of physiological probiotic properties of different lactic acid bacteria strains of dairy and human origin. J Funct Foods. 4:531-541.

https://doi.org/10.1016/j.jff.2012.02.014

34. NÁCHER VÁZQUEZ, M.; LÓPEZ, I.I.; NOTARARIGO, S.; FERNÁNDEZ, P.; FERNÁNDEZ, P. DE P.D.; AZNAR NOVELLA, R.; DUEÑAS CHASCO, M.T.; LÓPEZ GARCIA, P. 2016. Aplicaciones de los exopolisacáridos producidos por bacterias lácticas en la calidad y funcionalidad de los alimentos. En: Drider, D.; Rivera, V. Bacterias ácido lácticas. Fundamentos y aplicaciones. Alfaomega México. p.295-310.

35. PAIM, D.; COSTA, S.D.; WALTER, E.H.; TONON, R.V. 2016. Microencapsulation of probiotic jussara (Euterpe edulis M.) juice by spray drying. LWT. 74:21-25. https://doi.org/10.1016/j.lwt.2016.07.022

36. PULIDO, A.; BERISTAIN, C.I. 2010. Encapsulación de ácido ascórbico mediante secado por aspersión, utilizando quitosano como material de pared. Revista Mexicana de Ingeniería Química. 9(2):189-195.

37. RODRÍGUEZ, R.Y.A.; ROJAS, G.A.F; RODRÍGUEZ, B.S. 2016. Encapsulación de probióticos para aplicaciones alimenticias. Biosalud. 15(2):106-115.

https://doi.org/10.17151/biosa.2016.15.2.10

38. RODRÍGUEZ, S.; MONTES, L.; RAMÍREZ, D. 2012. Microencapsulación de probióticos mediante secado por aspersión en presencia de prebióticos. VITAE. 19(1):186188.
39. RODRIGUEZ-BARONA, S.; GIRALDO, G.; MONTES, L. 2016. Encapsulación de Alimentos Probióticos mediante Liofilización en Presencia de Prebióticos. Inf. tecnol. La Serena. 27(6):135-144. http://dx.doi.org/10.4067/S0718-07642016000600014

40. RUIZ, M.; COLELLO, R.; PADOLA, N.; ETCHEVERRÍA, A. 2017. Efecto inhibitorio de Lactobacillus spp. sobre bacterias implicadas en enfermedades transmitidas por alimentos, Revista Argentina de Microbiología. 49(2):174-177. https://doi.org/10.1016/j.ram.2016.10.005

41. SÁNCHEZ DE RAMOS, M.; DE DÍAZ, C.G.; MORÁN, A.E. 2011. Identificación de Escherichia coli O157: H7 en muestras de heces de pacientes con enfermedad diarreica aguda y en muestras de carne comercializadas en supermercados de San Salvador, El Salvador. Minerva Revista en Línea CIC-UES. 2(1):28-34.

42. SÁNCHEZ, L.; OMURA, M.; LUCAS, A.; PÉREZ, T.; LLANES, M.; FERREIRA, C.L. 2015. Cepas de Lactobacillus spp. con capacidades probióticas aisladas del tracto intestinal de terneros neonatos. Rev Salud Anim. 37(2):94-104.

43. SCHUBERT, H. 1993. Instantization of powdered food products. lnt Chemical Enginieering. 33:28-45.

44. SVETOSLAV, D.T.; O'TÁVIO, A.L.; DE PAULA, A.C.; CAMARGO, D.A.; LOPES, L.A. 2018. Combined effect of bacteriocin produced by Lactobacillus plantarum ST8SH and vancomycin, propolis or EDTA for controlling biofilm development by Listeria monocytogenes. Revista Argentina de Microbiología. 50(1):48-55.

https://doi.org/10.1016/j.ram.2017.04.011

45. TAGG, J.R.; MCGIVEN, A.R. 1971. Assay system for bacteriocins. Appl Microb. 21(5):943.

46. TOLEDO, E.; FALCON, N.; FLORES, C.; REBATTA, M.; GUEVARA, J.; RAMOS, D. 2015. Susceptibilidad antimicrobiana de cepas de Escherichia coli obtenidas de muestras de heces de cerdos destinados a Consumo Humano. Salud y Tecnología Veterinaria. 3(2):35-40. https://doi.org/10.20453/stv.v3i1.2823

47. VERA-MEJÍA, R.; ORMAZA-DONOSO, J.; MUÑOZCEDEÑO, J.; ARTEAGA-CHÁVEZ, F.; SÁNCHEZMIRANDA, L. 2018. Cepas de Lactobacillus plantarum con potencialidades probióticas aisladas de cerdos criollos. Revista de Salud Animal. 40(2):e04.

48. WENDLANDT, S.; SHEN, J.; KADLEC, K.; WANG, Y.; LI, B.; ZHANG, WJ.; SCHWARZ, S. 2015. Genes de resistencia a múltiples fármacos en estafilococos de animales que confieren resistencia a agentes antimicrobianos de gran importancia y crítica en la medicina humana. Tendencias en microbiología. 23(1):4. 